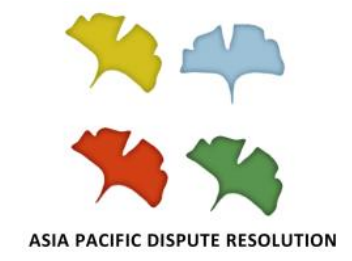

\title{
Deworming during Pregnancy and Birth Outcomes
}

\author{
Nisha Malhotra \\ Faculty of Arts \\ University of British Columbia \\ Devesh Roy \\ International Food Policy Research Institute \\ New Delhi, India
}

\section{APDR Working Paper Series \\ Volume 1 Number 1 \\ ISSN 2371-6304}

by Nisha Malhotra \& Devesh Roy, 2018.

This article is made available as part of the Asia Pacific Dispute Resolution Working Paper Series and is licensed under a Creative Commons Attribution-

NonCommercial-NoDerivatives 4.0 International License 


\title{
DEWORMING DURING PREGNANCY AND BIRTH OUTCOMES
}

\author{
Nisha Malhotra \\ Faculty of Arts \\ University of British Columbia \\ Devesh Roy \\ International Food Policy Research Institute \\ New Delhi, India
}

\section{Introduction}

Approximately $25 \%$ of Indian infants in the late 1990s were born with low birth weights (LBW). ${ }^{1}$ The consequences of LBW are severe and include infant mortality, impaired neurological and cognitive development in childhood, as well as an increased risk for a number of negative health conditions in adulthood. ${ }^{2}$ These include high blood pressure, diabetes, coronary heart disease, stroke, as well as emotional and mental imbalances. ${ }^{3}$

In India, nutritional anemia during pregnancy is one of the major causes of LBW status and perinatal mortality. ${ }^{4}$ In the latest national family health survey (NFHS 2005-06) 59 percent of

${ }^{1}$ UNICEF, "The State of the World's Children 2008: Child Survival" (New York: United Nations, 2008); International Institute for Population Sciences (IIPS) and Macro International, "National Family Health Survey (NFHS-3), 2005-06", vol 1 (Mumbai: IIPS, 2007) [IIPS, “NFHS-3”].

${ }^{2}$ Cesar G Victora, Fernando C Barros, J Patrick Vaughan \& Ana Maria B Teixeira, "Birthweight and Infant Mortality: A Longitudinal Study of 5914 Brazilian Children" (1987) 16:2 Int'l J Epidemiology 239; Rebecca Norton, "Maternal Nutrition during Pregnancy as it Affects Infant Growth, Development and Health" SCN News (1994) at 15-21; Janet W Rich-Edwards, Meir J Stampfer, JoAnn E Manson, Bernard Rosner, Susan E Hankinson, Graham A Colditz, Charles H Hennekens \& Walter C Willet, "Birthweight and Risk of Cardiovascular Disease in a Cohort of Women Followed up since 1976" (1997) 315:7105 British Medical J 396; JW Rich-Edwards, K Kleinman, KB Michels, MJ Stampfer, JE Manson, KM Rexrode, EN Hilbert \& WC Willet, "Longitudinal Study of Birth Weight and Adult Body Mass Index in Predicting Risk of Coronary Heart Disease and Stroke in Women" (2005) 330:7500 British Medical J 1115 [Rich-Edwards et al., "Predicting Risk of Coronary Heart Disease"]; Robert E Black, Lindsay H Allen, Zulfiqar A Bhutta, Laura E Caulfield, Mercedes de Onis, Majid Ezzati, Colin Mathers \& Juan Rivera, "Maternal and Child Undernutrition: Global and Regional Exposures and Health Consequences" (2008) 371:9608 Lancet 243.

${ }^{3}$ Rich-Edwards et al., "Predicting Risk of Coronary Heart Disease", supra note 2; DJP Barker, T Forsén, A Uutela, C Osmond \& JG Eriksson, "Size at Birth and Resilience to Effects of Poor Living Conditions in Adult Life: Longitudinal Study" (2001) 7324:323 British Medical J 1273; CHD Fall, M Vijayakumar, DJP Barker, C Osmond \& S Duggleby, "Weight in Infancy and Prevalence of Coronary Heart Disease in Adult Life" (1995) 310:6971 British Medical J 17.

${ }^{4}$ Premananda Bharati, Suparna Som, Suman Chakrabarty, Susmita Bharati \& Manoranjan Pal, "Prevalence of Anemia and Its Determinants Among Nonpregnant and Pregnant Women in India" (2008) 20:4 Asia-Pacific J Public 
pregnant women were anemic and 32 percent exhibited moderate to high anemia. ${ }^{5}$ In a study of 16 districts in India $84.9 \%$ of pregnant women $(n=6,923)$ were found to be anemic out of which $13.1 \%$ had severe anemia (haemoglobin $<70 \mathrm{~g} / \mathrm{L}){ }^{6}$

One major risk factor for the severity and persistence of anemia particularly in pregnant women is chronic blood loss from intestinal parasitic infections (IPI). ${ }^{7}$ IPI is an important contributor of low pregnancy weight gain and intrauterine growth retardation, which in turn leads to low birth weight. ${ }^{8}$ Intestinal parasitic infection is highly prevalent in India. In a rural part of southern India the overall prevalence of various parasitic infections was found to be $97.4 \%$ and the most common helminthic infection was hookworm infestations $(61.5 \%) .{ }^{9}$ In a low-income area in north India, $35.6 \%$ of pregnant women were found infected with at least one parasite. ${ }^{10}$ In a five-year study in Ujjain, central India, $27.4 \%$ of the women were found to be infected with intestinal parasites. ${ }^{11}$

Health 347; Usha Ramakrishnan \& Beth Imhoff-Kunsch, "Anemia and Iron Deficiency in Developing Countries" in Carol J Lammi-Keefe, Sarah C Couch \& Elliot H Philipson, eds, Handbook of Nutrition and Pregnancy (Totawa, NJ: Humana Press, 2008) 337; Parul Christian, Subarna K Khatry \& Keith P West, Jr., "Antenatal Anthelmintic Treatment, Birthweight, and Infant Survival in Rural Nepal" (2004) 364:9438 Lancet 981.

${ }^{5}$ IIPS, supra note 1; KN Agarwal, DK Agarwal, A Sharma, K Sharma, K Prasad, MC Kalita, N Khetarpaul, AC Kapoor, L Vijayalekshmi, AK Govilla, SM Panda \& P Kumari, "Prevalence of Anemia in Pregnant \& Lactating Women in India" (2006) 124:2 Indian J Medical Research 173.

${ }^{6}$ GS Toteja, Padam Singh, BS Dhillon, BN Saxena, FU Ahmed, RP Singh, Balendu Prakash, K Vijayaraghavan, Y Singh, A Rauf, UC Sarma, Sanjay Gandhi, Lalita Behl, Krishna Mukherjee, SS Swami, Viu Meru, Prakash Chandra, Chandrawati \& Uday Mohan, "Prevalence of Anemia among Pregnant Women and Adolescent Girls in 16 Districts of India" (2006) 27:4 Food \& Nutrition Bull 311.

${ }^{7}$ Simon Brooker, Peter J Hotez, Donald AP Bundy, "Hookworm-Related Anaemia among Pregnant Women: A Systematic Review" (2008) 2:9 PLoS Neglected Tropical Diseases e291.

${ }^{8}$ Roberto Rodriguez-Garcia, Leoncio Miguel Rodriguez-Guzman, María Isabel Sánchez-Maldonado, Alejandro Gómez-Delgado \& Roberto Rivera-Cedillo, "Prevalence and Risk Factors Associated with Intestinal Parasitoses in Pregnant Women and Their Relation to the Infant's Birth Weight" (2002) 70 Ginecología y Obstetricia de México 338; Mamie-Eleanor Sackey, M Margaret Weigel, Rodrigo X Armijos. "Predictors and Nutritional Consequences of Intestinal Parasitic Infections in Rural Ecuadorian Children" (2003) 49:1 J Tropical Pediatrics 17; Alfonso J Rodríguez-Morales, Rosa A Barbella, Cynthia Case, Melissa Arria, Marisela Ravelo, Henry Perez, Oscar Urdaneta, Gloria Gervasio, Nestor Rubio, Andrea Maldonado, Ymora Aguilera, Anna Viloria, Juan J Blanco, Magdary Colina, Elizabeth Hernández, Elianet Araujo, Gilberto Cabaniel, Jesús Benitez \& Pedro Rifakis, "Intestinal Parasitic Infections among Pregnant Women in Venezuela" [2006] Infectious Diseases Obstetrics \& Gynecology 23125.

${ }^{9}$ Gagandeep Kang, Mary S Mathew, D Prasanna Rajan, Jasper D Daniel, Minnie M Mathan, VI Mathan \& JP Muliyil, "Prevalence of Intestinal Parasites in Rural Southern Indians" (1998) 3:1 Tropical Medicine \& Int'l Health 70.

${ }^{10}$ Sehgal R, Gogulamudi V Reddy, Jaco J Verweij \& Atluri V Subba Rao, "Prevalence of Intestinal Parasitic Infections among School Children and Pregnant Women in a Low Socio-economic Area, Chandigarh, North India" (2010) 1:2 Rev Infection 100.

${ }^{11}$ Yogyata Marothi \& Binita Singh, "Prevalence of Intestinal Parasites at Ujjain, Madhya Pradesh, India: Five-Year Study” (2011) 5:18 Af J Microbiology Research 2711. 
In 2002, the World Health Organization recommended deworming (using anti-helminthic drugs like albendazole or mebendazole) for pregnant women in their 2nd or 3rd trimester in areas where the prevalence of IPI exceeds $20-30 \%$, as is the case in India. ${ }^{12}$ The effect of deworming has been shown to vary according to the intensity of the infection and administration of the drug. In Uganda for a sample with high helminthic prevalence there was no overall effect of anthelminthic use during pregnancy on birth weight. ${ }^{13}$ In contrast, for a sample in rural Nepal with comparable prevalence but a higher infection intensity, deworming had significant effects on birth outcomes. ${ }^{14}$ Location-specific results cast doubts on the external validity of the experiments and the present study mitigates some of the concerns relating to location specificity for India by using a nationally representative data.

Overall there are very few studies on the effect of deworming during pregnancy on birth outcomes for India and to our knowledge, prior studies have not focused on deworming and birth outcomes using nationally representative data for India. Given the evidence of benefits of deworming in other countries, further studies are required to make a case for a deworming program in national antenatal health care package for India. ${ }^{15}$

Our cross-sectional study builds on the existing research about deworming and birth weight across twenty-nine states in India. The setting for impact evaluation (nationwide) is such that randomized trials are not practical. This study identifies the effect of deworming during pregnancy on birth weight by matching households in a nationally representative sample. We include the pathway of worm infection by accounting for water quality and water treatment

\footnotetext{
${ }^{12}$ World Health Organization, "Deworming for Health and Development: Report of the Third Global Meeting of the Partners for Parasite Control" (Geneva: WHO, 2005), online: <www.who.int/neglected_diseases/resources/WHO_CDS_CPE_PVC_2005.14/en/>, accessed March 15, 2018 [WHO, "Partners for Parasite Control"]; World Health Organization, "Preventive Chemotherapy in Human Helminthiasis: Coordinated Use of Anthelminthic Drugs in Control Interventions: A Manual for Health Professionals and Programme Managers" (Geneva: WHO, 2006), online: <apps.who.int/iris/bitstream/10665/43545/1/9241547103_eng.pdf>, accessed March 15, 2018.

${ }_{13}$ J Ndibazza, L Muhangi, D Akishule, M Kiggundu, C Ameke, J Oweka, R Kizindo, T Duong, I Kleinschmidt, M Muwanga and AM Elliott, "Effects of Deworming During Pregnancy on Maternal and Perinatal Outcomes in Entebbe, Uganda: A Randomized Controlled Trial" (2010) 50:4 Clinical Infectious Diseases 531; World Health Organization, "Maternal Anthropometry and Pregnancy Outcomes: A WHO Collaborative Study" (1995) 73:Supp Bull World Health Organization 1 [WHO, "Maternal Anthropometry"]; World Health Organization, "Iron Deficiency Anaemia: Assessment, Prevention, and Control: A Guide for Programme Managers" (2001) WHO/NHD/01.3.

${ }^{14}$ Christian, Khatry \& West, supra note 4.

${ }^{15}$ Brooker, Hotez \& Bundy, supra note 7.
} 
practices followed by households. Also, other socioeconomic covariates are included in the analysis. We hypothesize that women taking deworming drugs during pregnancy would be less likely to have an infant with LBW and all else being equal the benefit of deworming is hypothesized to be higher where quality of potable water is inferior. ${ }^{16}$

\section{Data}

The National Family Health Survey (NFHS-3) conducted in $2005-06^{17}$ was used in this paper. The survey collected information from 124,385 eligible women aged 15-49 in 29 states of the country. The survey provided information on infants born in the five years preceding the survey and mothers' characteristics as well as any intake of deworming drugs during pregnancy. ${ }^{18}$ The NFHS-3 also provided information on the practices related to water treatments by households that would determine the quality of potable water and in turn would be relevant for possibility of waterborne parasites causing infection.

\subsection{Outcome Measure}

Birth weight (in grams) was obtained from written records (recorded on health cards) and in a few cases mother's memory (recall). Data for birth weight was obtained for infants that were born up to 5 years preceding the 2005-06 survey. We use two outcome measures: (1) birth weight, and (2) a dichotomous variable for low birth weight (defined as <2500 g), which takes the value of 1 if the birth weight was lower than 2500 grams and 0 otherwise.

\subsection{Exposure Variable: Access to Deworming Drugs}

The survey asked mothers, "During this (last) pregnancy, did you take any drug to get rid of worms in your intestines?"19 A dichotomous variable was created to investigate the presence or absence of deworming drugs (treatment and control respectively) in pregnant woman's

\footnotetext{
${ }^{16}$ Sehgal et al., supra note 10.

${ }^{17}$ Funding for NFHS-3 was provided by the United States Agency for International Development (USAID), the United Kingdom Department for International Development (DFID), the Bill and Melinda Gates Foundation, UNICEF, UNFPA, and the Government of India. Technical assistance for NFHS-3 was provided by Macro International, Maryland, USA. Eighteen research organizations conducted fieldwork for NFHS-3. Thirteen of these are private sector research organizations and five are Population Research Centres (PRCs) established by the GOI in various states.

${ }^{18}$ International Institute for Population Sciences (IIPS) \& ORC Macro, "National Family Health Survey (NFHS-2), 1998-99: India" (Mumbai: IIPS, 2000), online: 〈https://dhsprogram.com/pubs/pdf/frind2/frind2.pdf>, accessed March 15, 2018. In India, NFHS-3 did not measure 9 percent of infants under age five. Also excluded from the analysis are 8 percent of eligible infants whose month and year of birth were not known or who had grossly improbable height or weight measurements.

19 "Never" and "occasionally" were grouped together.
} 
medication routine. ${ }^{20}$ The variable took the value 1 if pregnant women took the deworming drug and a value of 0 otherwise.

\subsection{Covariates}

It is important to stratify household's access to deworming drugs by quality of potable water. In the survey, households used various treatments to improve the quality of water. These practices were clubbed into three groups: strong treatment (boil, bleach, and alum), mild treatment (strain, filter, and letting water stand), and no treatment (reference group). Three binary variables were created for each of the three categories.

Other variables used to match infants were: mother's age at the time of birth; mother's education (number of years of schooling); Mother's work status (1 if mother currently worked or worked in the last 12 months); mother's primacy in making decisions relating to health (1 if she was allowed to visit a health care facility on her own and 0 otherwise). Other variables used for matching included whether the child was mother's first born ( 1 if yes and 0 otherwise); intake of iron and folic acid tablets by the woman during pregnancy ( 1 if yes and 0 otherwise).

Diversity of maternal diet was captured by a categorical variable (valued from 1 to 6) accounting for the number of food groups consumed by the mother in the last 24 hours: Food group categories are comparable to those used in previous literature and are milk, cheese, yogurt, or other milk products; bread, noodles, or other food made from grains; oil, fats, butter, or products made from them; mangoes, papaya, or other Vitamin A rich fruits; beans, legumes/lentils, and nuts; other fruits and vegetables (including green leafy vegetables); eggs, meat, poultry, fish, and shellfish (and organ meats). ${ }^{21}$ Data on the presence and content of iodine in household salt at the time of the survey were also collected ( 0 if salt was not fortified, 1 if salt contained less than 15 parts per million of iodine and a value of 2 if salt contained 15 parts per million of iodine).

\footnotetext{
${ }^{20}$ Albendazole 2 tablets are the most common drug given during pregnancy for deworming. In later pregnancy six $100 \mathrm{mg}$ tablets of mebendazole is safer. Treatment is not recommended in the first trimester. Both are supposed to be available at any Public Health Center.

${ }^{21}$ See-Ling Loy, M Marhazlina, Y Nor Azwany, JM Hamid Jan, "Higher Intake of Fruits and Vegetables in Pregnancy is Associated with Birth Size" (2011) 42:5 Southeast Asian J Tropical Medicine \& Public Health 1214; Bernadette P Marriott, Alan White, Louise Hadden, Jayne C Davies, John C Wallingford, "World Health Organization (WHO) Infant and Young Child Feeding Indicators: Associations with Growth Measures in 14 LowIncome Countries" (2011) 8:3 Maternal \& Child Nutrition 354.
} 
Wealth index was divided into quintiles for the whole sample: poorest (the reference group), poorer, middle, richer, and richest. The wealth index was based on asset ownership and housing characteristics of each household (for example, type of flooring, cooking fuel, ownership of a car, etc.) and principal component analysis was used to assign weights to each asset, which was then standardized and households were ranked according to their aggregate asset scores. A binary variable 'scheduled caste or tribe' takes a value of 1 if the household belonged to scheduled caste (reflects social segregation and hence access to health care and other amenities) or scheduled tribe (classified by the government of India on the basis of geographical isolation in remote areas).

Whether or not a public health center existed at the place of residence, and the distance and cost of travel to the nearest one were also accounted for in matching comparable cases. Under the Integrated Child Development Scheme, the Government of India has set up Anganwadi centres (AWC), public health centers which provide nutrition, health, and education services to mothers with children less than six years of age. ${ }^{22}$ A binary variable Anganwadi was created that took the value 1 if households had access to an Anganwadi centre and 0 otherwise. Distance to the health facility and cost of the health facility are ordinal variables that take one of three values according to whether the family has no problem (0), not a big problem (1), or too big a problem (2) in traveling to the health facility or for the cost of the health facility. As in many cases households share toilets, a variable was created for the number of households sharing their toilets.

\section{Methods}

A basic treatment model aims to identify the impact of "treatment", $d$, on outcome $y$. Let $d=1$ imply treatment (intake of deworming drugs) and $d=0$ imply no treatment (i.e., the control group). The treatment model is thus specified as:

$$
y_{i}=\alpha+X_{i} \beta+\delta d_{i}+\epsilon_{i}
$$

If $d$ is a discrete treatment then estimated value of $\delta$ is termed as the average effect of the treatment on the treated (ATT).

\footnotetext{
${ }^{22}$ Ministry of Women and Child Development (Food and Nutrition Board), "National Guidelines on Infant and Young Child Feeding", 2nd ed (New Delhi: Government of India, 2006), online: <wcd.nic.in/sites/default/files/infantandyoungchildfeed.pdf>, accessed March 15, 2018.
} 
In order to ascertain ATT we need to know the counterfactual, i.e., the outcome of the treated group if they were not subject to treatment. By randomly assigning pregnant women into treatment and control groups, one can directly construct the counterfactual. ${ }^{23}$ Under situations where random assignment cannot be implemented, an alternative approach is matching by pairing each program participant with an observationally similar nonparticipant and interpreting the difference in their outcomes as the effect of the program. ${ }^{24}$ Propensity score matching (PSM) matches treated and untreated observations based on the estimated probability of being treated (propensity score).

PSM constructs a statistical comparison group based on a model of the probability of participating in the treatment: $P(X)=\operatorname{Pr}(d=1 \mid X)$. Rosenbaum and Ruben showed that under certain assumptions, matching on $P(X)$ is as good as matching on $\mathrm{X} .{ }^{25}$ Propensity score, $\mathrm{P}(\mathrm{X})$, is constructed from a probit model of program participation controlling for all $\mathrm{X}$ variables that jointly affect the probability of participation and the outcome of interest.

In the impact assessment of deworming drugs on birth weight we matched observationally similar pregnant women who took the deworming drug (treatment group) to pregnant women that did not take the deworming drug (control group).

The propensity score matching strategy aims to overcome the potential sources of biases arising from differences in pre-existing conditions between treatment and control groups when the mother can be affected by worm-related infection. The list of individual, household, and location-specific characteristics included as covariates are therefore those that have a high probability of influencing intake of deworming drugs, as well as outcome (i.e., birth weight). Different matching estimators were implemented using a bias corrected nearest neighbour

\footnotetext{
${ }^{23}$ James J Heckman, Hidehiko Ichimura \& Petra E Todd, "Matching As An Econometric Evaluation Estimator: Evidence from Evaluating a Job Training Programme" (1997) 64 Rev Econ Stud 605.

${ }^{24}$ Jeffrey A Smith \& Petra E Todd, "Does Matching Overcome Lalonde's Critique of Nonexperimental Estimators?" (2005) 125:1-2 J Econometrics 305.

${ }^{25}$ Paul R Rosenbaum \& Donald B Rubin, "The Central Role of the Propensity Score in Observational Studies for Causal Effects (1983) 70:1 Biometrika 41.
} 
matching estimator and kernel matching method. ${ }^{26}$ The former was selected for reporting because analytical standard errors are possible for estimates of treatment effects.

Estimators proposed in combine matching with the bias correction proposed in Rubin and Quade and a non-parametric extensions of this bias correction. ${ }^{27}$ The difference in outcomes between the treatment and control groups that have similar propensity scores (conditional on the set of observed covariates) gives the average effect of the treatment (taking deworming drugs during pregnancy) on the treated (infants of mothers who took deworming drugs).

Univariate regressions were also carried out with: a) birth weight in grams as the outcome, and b) low birth weight $(<2500 \mathrm{~g})$ as the dichotomous outcome variable. All data analyses were performed using the Stata software package version 12.0. ${ }^{28}$

We also test if these results are sensitive to the model design of the nearest neighbour matching, we report results for three separate cases where we vary the "numbers of neighbours matched" from 1, 3, and 5. ${ }^{29}$ The main outcome of interest was ATT though Average Treatment Effect on the Control Group (ATC) i.e. potential average effect of deworming on child birth weight in the group without intake of deworming drugs and combined Average Treatment Effect on both treatment and control groups (ATEs) were also reported.

\subsection{Ethics Statement}

NFHS is the Indian component of the Measure Demographic Health survey project, which is secondary data and is made publicly available for research purposes; therefore, no ethics statement was required.

\section{Results}

Table 1 reports the summary statistics for all the variables used in this analysis. In the sample, 37 percent of the infants weighed less than 2500 grams, 22 percent weighed less than 2000 grams, and about 4 percent weighed less than 1500 grams. The majority of pregnant women were in

\footnotetext{
${ }^{26}$ Alberto Abadie \& Guido W Imbens, "On the Failure of the Bootstrap for Matching Estimators" (2008) 76:6 Econometrica 1537.

${ }^{27}$ Ibid; Donald B Rubin, "Matching to Remove Bias in Observational Studies" (1973) 29:1 Biometrics 159; Dana Quade, "Nonparametric Analysis of Covariance by Matching" (1982) 38:3 Biometrics 597.

28 "Data Analysis and Statistical Software | Stata" (College Station, TX), online: <https://www.stata.com/>, accessed March 15, 2018.

${ }^{29}$ Abadie \& Imbens, supra note 26.
} 
households that had no treatment for water, making them most vulnerable to waterborne infections. Importantly, these households with less or no treatment of water also showed lower access to deworming drugs. Around five percent of the women in the sample had taken a deworming drug during their last pregnancy. The majority of the infants, roughly $80 \%$, belonged to a Hindu household. The mean birth weight for the sample was relatively low at 2815.94 grams. Iron and Folic acid tablets were taken by $67 \%$ of the women during pregnancy.

The average treatment effect of deworming drugs on infant's birth weight was modeled using PSM involving nearest neighbour matching. Based on matching, the infants born in observed comparable situations tended to have lower birth weight if the mother was not treated with deworming drugs during pregnancy. The ATT was approximately 66 grams (Table 2a), and there was also a 2.2 percentage point reduction in the probability of LBW (Error! Reference source not found.2b).

Sensitivity test for the neighbour matching design is reported in table 3 . The results are similar across different cases and are significant in all cases. To account for non-linearity in the effects of deworming drugs for pregnant mothers on child birth weight, the effect on the binary outcome of having less weight than a cutoff value was also analyzed (1500, 2000, and 2500 grams respectively). Only the case of 2500 grams is reported. The effects for all the above cutoff cases were found to be significant, and the ATE for cutoff of 1500 grams was the lowest and the case for the cutoff of 2500 grams was the highest.

\section{Discussion}

This study showed benefits of deworming during pregnancy (2nd and 3rd trimester) for birth outcomes in the Indian sample. Either albendazol or mebendazole was prescribed at the public health facility. Public health facilities are equipped with Albendazol (400mg, 1 tablet) and Mabendazol (100 mg twice daily for 3 days), and are under guidelines by the Ministry of Women and Child Development to administer these in cases of anemia during pregnancy. ${ }^{30}$

We hypothesized the pathway to be through the link with iron deficiency anemia (IDA) that could occur in the absence of deworming. One of the direct implications of IDA is low birth

\footnotetext{
${ }^{30}$ Manoj Kumar Rai \& Jyothi Vailaya, "The National Nutrition Scene: An Analysis of Results of Two National Surveys" (1996) 33:4 Indian Pediatrics 305.
} 
weight of babies. The effect of deworming drugs in this study was potentially underestimated yet the assessed values were quite sizable in relation to the birth weights in the category of lowest and second lowest quartiles of birth weight distribution.

The results in this study conform to the findings in other studies. In a program in Sri Lanka, pregnant women received IFA in their first trimester and were offered a single dose of mebendazole in their second trimester. Results showed that the proportion of very low birth weight babies $(<1500 \mathrm{~g})$ was lower in the treated group $-1.1 \%$ versus $2.3 \%$ in the control group. ${ }^{31}$ In a randomized trial in Nepal, birth weights of infants born to women who had received two doses of albendazole in the second trimester were higher by $59 \mathrm{~g}$ compared to women who had not taken albendazole. ${ }^{32}$ These numbers are strikingly similar to the ATT obtained from matching estimation in our study.

In a study in West Bengal, India, among the severely anemic mothers, group that was given a dose of 400mg albendazole at 28-30 weeks of gestation in addition to $200 \mathrm{mg}$ ferrous sulphate tablets (twice daily) observed a $196.7 \mathrm{~g}$ higher birth weight. ${ }^{33}$ These numbers are much larger than what we obtained in our current study, and this might be because (a) both the treatment and control group in comprised only severely anemic women and (b) the treatment consisted of deworming and IFA supplementation while treatment in our study is confined to deworming drugs. ${ }^{34}$

Combining these findings, the case for deworming as part of antenatal care is quite strong in countries with high prevalence of parasitic infection, especially since there is little or no evidence or reports of adverse side effects in mothers or adverse birth outcomes in infants. ${ }^{35}$ The case for these drugs is also strengthened based on simple cost-benefit considerations since these drugs are largely inexpensive. The cost is less than US\$0.02 per tablet in most countries. Iron

${ }^{31}$ TM Sunethra Atukorala, L Dilip R De Silva, Wim HJC Dechering, T Stanley de C Dassenaeike \& Rajitha S Perera, "Evaluation of Effectiveness of Iron-Folate Supplementation and Anthelminthic Therapy against Anemia in Pregnancy: A Study in the Plantation Sector of Sri Lanka" (1994) 60:2 Am J Clinical Nutrition 286.

${ }^{32}$ Christian, Khatry \& West, supra note 4.

${ }^{33}$ Bhattacharya S \& Patil SP, "Should Albendazole Be Included in Antenatal Package in Hookworm Endemic Zone like India?" (2009) 59:4 J Obstetrics \& Gynecology India 332.

${ }^{34}$ Ibid.

${ }^{35}$ NR de Silva, JLGJ Sirisena, DPS Gunasekera, MM Ismail \& HJ de Silva, "Effect of Mebendazole Therapy during Pregnancy on Birth Outcome" (1999) 353:9159 Lancet 1145; Theresa W Gyorkos, Renee Larocque, Martin Casapia \& Eduardo Gotuzzo, "Lack of Risk of Adverse Birth Outcomes after Deworming in Pregnant Women" (2006) 25:9 Pediatric Infectious Disease J 791. 
supplementation in comparison has been estimated at US\$21.39 per pregnant woman per year in South America. ${ }^{36}$

Contributing factors of worm related infections like low quality of potable water, poor sanitation systems, and unhygienic living conditions would require time and resources to address. Thus, an immediate solution of including deworming in maternal health package becomes important in bringing down the incidence of low birth weight and addressing the high rates of child malnutrition in India.

In 2002, the WHO released new guidelines recommending deworming during pregnancy after the first trimester in areas with high prevalence of parasitic infections. ${ }^{37}$ Currently, among countries with a high prevalence of parasitic infection, Sri Lanka and Nepal are the only two countries that have included deworming in their routine antenatal care programs. ${ }^{38}$ Since the inclusion of deworming both countries have reduced the prevalence of anemia among pregnant women. In India, the ineffectiveness of the national nutritional programs and increasing rates of anemia among pregnant women might be partly explained by high prevalence of untreated parasitic infections. ${ }^{39}$ The lack of uptake by the Indian government for this low cost intervention needs more attention, and further studies to understand the effectiveness of deworming programs during pregnancy in different regions of India are warranted.

Our adopted methodology has implications for several similar and interrelated concepts. With data on individual, household, and community characteristics, effects of different measures on health outcomes could be estimated. For example a straightforward application of the method could be to assess the effect of dietary patterns on health outcomes.

There were some limitations to our study. First, the treatment variable assumed a value of 0 for all cases where drug was not used irrespective of whether or not there was a worm-related infection. The treatment effect could thus be underestimated relative to a control group that comprised only women who were infected but did not take deworming drugs. Second, the

\footnotetext{
${ }^{36}$ Renée Larocque \& Theresa W Gyorkos, "Should Deworming Be Included in Antenatal Packages in HookwormEndemic Areas of Developing Countries?” (2006) 97:3 Can J Public Health 222.

37 WHO, "Maternal Anthropometry", supra note 13.

${ }^{38}$ WHO, "Partners for Parasite Control" supra note 12.

${ }^{39}$ IIPS, "NFHS-3", supra note 1; Black et al., supra note 2.
} 
treatment variable does not distinguish between the numbers of times the deworming drug was taken and if the drugs rid them of all infection. If only a subset of infections were treated then again the effects would have been underestimated. The third point is the missing data on birth weight - another reason the effects could be underestimated. Since the infants that were not weighed most likely lacked access to a formal health care system, they would therefore be more prone to adverse health outcomes. In summary these limitations generally would have produced an underestimate of the effects of the treatment rather than an overestimate.

\section{Conclusions}

This study provides evidence for the importance of deworming drugs on the birth weight of infants. Further, in a situation that precludes use of controlled trials, the analysis applied a unique approach to modeling the counterfactual scenario that demonstrated intake of deworming drugs by pregnant women on average raised the birth weight of infants. Lack of treatment for parasitic infection through drugs could undermine infant and maternal health particularly in vulnerable groups. Access to deworming drugs in certain contexts could be of public health significance. In view of these findings, there is a need to protect pregnant women from IDA that could result from hookworms or other such infections.

Information campaigns as well as interventions should be directed in part towards prevention of morbidity. Information regarding treatment of potable water, for example, should be publicized. Similarly, programs to improve sanitation would constitute an important preventive step towards helminthic and other parasitic infections. Improving diets that prevent micronutrient deficiencies (and prevent anemia) should also be promoted. In addition to providing iron supplementation, biofortification (with micronutrients) of staple foods that constitute a major share of the diet of the poor should also be considered.

Since the estimated effects of deworming on birth outcomes have varied across countries — with some studies showing little or no effect and others showing significant effects-there are concerns relating to location specificity, and this study lessens such concerns by showing results at a national level. 


\section{Figure 1: Conceptual framework for effect of deworming}

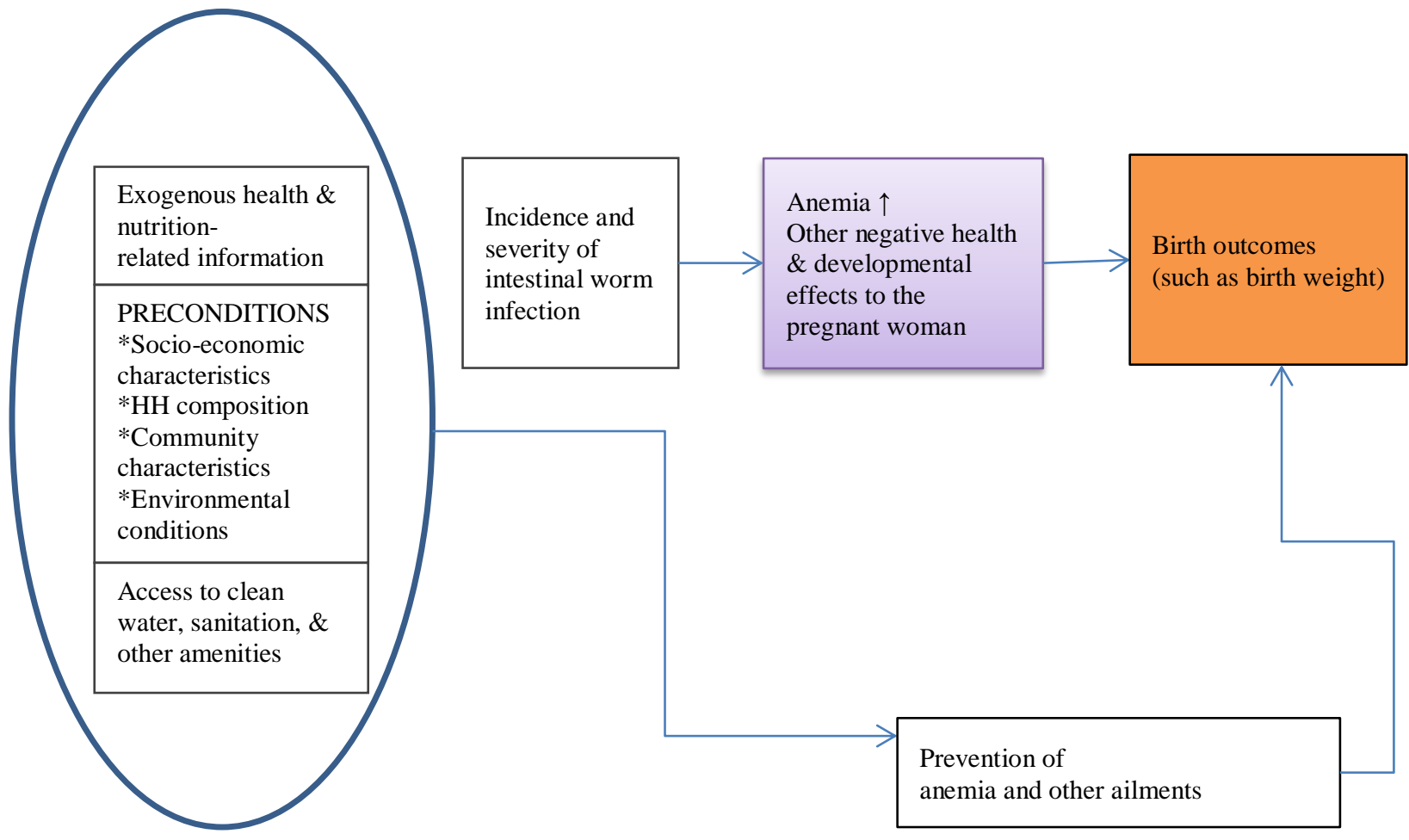


Table 1: Socio-Demographic Characteristics of Mothers (India NFHS III (2005-2006))

\begin{tabular}{|c|c|c|c|c|c|}
\hline \multirow{3}{*}{ Variable } & \multicolumn{2}{|c|}{ Birthweight $>2500 \mathrm{~g}$} & \multicolumn{2}{|c|}{ Birthweight $<2500 \mathrm{~g}$} & \multirow{3}{*}{$\mathrm{P}$ value } \\
\hline & \multirow{3}{*}{$\mathrm{N}$} & $\%$ or & \multirow[b]{2}{*}{$\mathrm{N}$} & \multirow{2}{*}{$\begin{array}{c}\% \text { or } \\
\text { Mean } \pm \text { SD }\end{array}$} & \\
\hline & & Mean \pm SD & & & \\
\hline Water Treatment - safe to drink & & & & & $<0.000$ \\
\hline Water is not Treated & 4426 & 41.11 & 3149 & 0.5 & \\
\hline Mildly Treated (strain,filter,stand,) & 3455 & 21.72 & 1965 & 0.31 & \\
\hline Severely Treated (boil,bleach,elec,alum) & 4001 & 37.17 & 1708 & 0.27 & \\
\hline \multicolumn{6}{|l|}{ Deworming Drug } \\
\hline Yes & 518 & 0.05 & 246 & 0.04 & \\
\hline \multicolumn{6}{|l|}{ No } \\
\hline Currently working/worked in last 12 months & & & & & 0.165 \\
\hline Yes & 2983 & 27.71 & 1698 & 26.73 & \\
\hline No & 7782 & 72.29 & 4654 & 73.27 & \\
\hline Decision to access Health Care & & & & & $<0.000$ \\
\hline Yes & 7339 & 68.17 & 4093 & 64.44 & \\
\hline No & 3426 & 31.83 & 2259 & 35.56 & \\
\hline Child: First Born & & & & & 0.065 \\
\hline Yes & 4706 & 43.72 & 2869 & 0.45 & \\
\hline \multicolumn{6}{|l|}{ No } \\
\hline \multicolumn{6}{|l|}{ Taken Iron Folic Acid Tablet/Syrup } \\
\hline Yes & 7396 & 0.69 & 4181 & 0.66 & \\
\hline \multicolumn{6}{|l|}{ No } \\
\hline \multicolumn{6}{|l|}{ Number of Food Groups Consumed } \\
\hline 1 Food Group & 80 & 0.01 & 41 & 0.01 & \\
\hline 2 Food Groups & 345 & 0.03 & 205 & 0.03 & \\
\hline 3 Food Groups & 1172 & 0.11 & 806 & 0.13 & \\
\hline 4 Food Groups & 2067 & 0.19 & 1488 & 0.23 & \\
\hline 5 Food Groups & 3241 & 0.3 & 1966 & 0.31 & \\
\hline 6 Food Groups & 2075 & 0.19 & 1062 & 0.17 & \\
\hline \multicolumn{6}{|l|}{ Iodine fortification of Salt } \\
\hline 0 : Salt is not fortified with Iodine & 1559 & 0.16 & 1107 & 0.19 & \\
\hline $1:<15$ parts per million of Iodine & 1405 & 0.14 & 884 & 0.15 & \\
\hline $2:>=15$ parts per million of Iodine & 7039 & 0.7 & 3908 & 0.66 & \\
\hline \multicolumn{6}{|l|}{ Wealth Index } \\
\hline Poorest & 482 & 0.04 & 407 & 0.06 & \\
\hline Poorer & 856 & 0.08 & 671 & 0.11 & \\
\hline Middle & 1777 & 0.17 & 1186 & 0.19 & \\
\hline Richer & 3130 & 0.29 & 1813 & 0.29 & \\
\hline Richest & 4520 & 0.42 & 2275 & 0.36 & \\
\hline Schedule Caste or Schedule Tribe & 2942 & 0.28 & 1634 & 0.27 & \\
\hline \multicolumn{6}{|l|}{ Yes } \\
\hline NO & & & & & \\
\hline
\end{tabular}


HH covered by Anganwadi/ICDS

\begin{tabular}{|c|c|c|c|c|c|}
\hline Yes & 7685 & 0.71 & 4437 & 0.7 & \\
\hline \multicolumn{6}{|l|}{ No } \\
\hline \multicolumn{6}{|l|}{ Distance to health facility } \\
\hline not a problem & 7073 & 0.66 & 3882 & 0.61 & \\
\hline minor problem & 2233 & 0.21 & 1445 & 0.23 & \\
\hline major problem & 1453 & 0.14 & 1024 & 0.16 & \\
\hline \multicolumn{6}{|l|}{ Cost of health facility } \\
\hline not a problem & 7644 & 0.71 & 4245 & 0.67 & \\
\hline minor problem & 2048 & 0.19 & 1331 & 0.21 & \\
\hline major problem & 1067 & 0.1 & 776 & 0.12 & \\
\hline Number of households sharing toilet & 10765 & $4.22 \pm$ & 6352 & 5.24 & 0.001 \\
\hline Mother's Age & 10765 & $27.52 \pm 4.94$ & 6352 & $26.79+4.86$ & $<0.001$ \\
\hline Mother's: Years of education & 10765 & $8.53 \pm 4.88$ & 6352 & $7.58 \pm 4.88$ & $<0.001$ \\
\hline
\end{tabular}

Results are expressed as means or numbers (\%). 
Table 2a: Estimated effect of deworming during pregnancy on birth weight

\begin{tabular}{|l|l|l|l|}
\hline \multicolumn{4}{|l|}{ Outcome Variable: Birth weight (in grams) } \\
\hline & Coefficient & Standard Error & P value \\
\hline Univariate OLS & 71.42 & 24.75 & 0.004 \\
\hline Propensity Score Matching (ATT) & 65.59 & 29.1 & 0.02 \\
\hline
\end{tabular}

OLS: Ordinary Least Square regression; ATT: Average treatment effect on the treated. Propensity Score matching is based on all the covariates listed in table 1; specification of the model-number of neighbours used for matching in PSM $=3$.

Table 2b: Estimated effect of deworming during pregnancy on birth weight

\begin{tabular}{|l|l|l|l|}
\hline \multicolumn{4}{|l|}{ Outcome Variable: A dichotomous variable for low birth weight (defined as <2500g) } \\
\hline & Coefficient & Standard Error & P value \\
\hline Univariate Logistic regression & -.227 & .079 & 0.004 \\
\hline Propensity Score Matching (ATT) & -.022 & .013 & 0.09 \\
\hline
\end{tabular}

ATT: Average treatment effect on the treated; Propensity Score matching is based on all the covariates listed in table 1; specification of the model-number of neighbours used for matching in PSM $=3$. 
Table 3a: Additional results and sensitivity tests for the estimated effects of deworming using PSM (Outcome variable: A dichotomous variable for low birth weight (defined as $<2500 \mathrm{~g}))$

\section{Sensitivity Test ${ }^{\mathrm{a}}$}

\begin{tabular}{|c|c|c|c|c|c|c|c|c|c|}
\hline \multicolumn{2}{|l|}{$\begin{array}{l}\text { Number of } \\
\text { neighbours used for } \\
\text { matching }\end{array}$} & \multicolumn{3}{|l|}{3} & \multicolumn{2}{|l|}{1} & \multicolumn{2}{|c|}{5} & \multirow[b]{2}{*}{$\begin{array}{l}\mathbf{P} \\
\text { value }\end{array}$} \\
\hline & & SE & $\begin{array}{l}\mathbf{P} \\
\text { value } \\
\end{array}$ & & SE & $\begin{array}{l}\mathbf{P} \\
\text { value }\end{array}$ & & SE & \\
\hline $\begin{array}{l}\text { Average treatment } \\
\text { effect on the treated }\end{array}$ & $-.022 *$ & .013 & 0.09 & $-.028 *$ & .017 & 0.10 & $-.023^{* *}$ & .012 & 0.05 \\
\hline $\begin{array}{l}\text { Average treatment } \\
\text { effect }\end{array}$ & $-.038 * * *$ & .014 & 0.007 & $-.042 * * *$ & .015 & 0.004 & $-.038 * * *$ & .013 & 0.005 \\
\hline $\begin{array}{l}\text { Average treatment } \\
\text { on the control }\end{array}$ & $-.038 * * *$ & .014 & 0.006 & $-.043 * * *$ & .015 & 0.004 & $-.039 * * *$ & .013 & 0.005 \\
\hline $\begin{array}{l}\text { * significant at } 10 \% \text { lev } \\
* * \text { significant at } 5 \% \text { lev } \\
* * * \text { significant at } 1 \% \text { le } \\
\text { a To test for sensitivity } \\
\text { used for matching in } \mathrm{PS}\end{array}$ & $\begin{array}{l}\text { el, } \\
\text { the results }\end{array}$ & speci & cation $\mathrm{c}$ & he model, s & pecific & y to the & ice of nu & ber of & ighbour \\
\hline
\end{tabular}

Sensitivity Test $^{\mathrm{a}}$

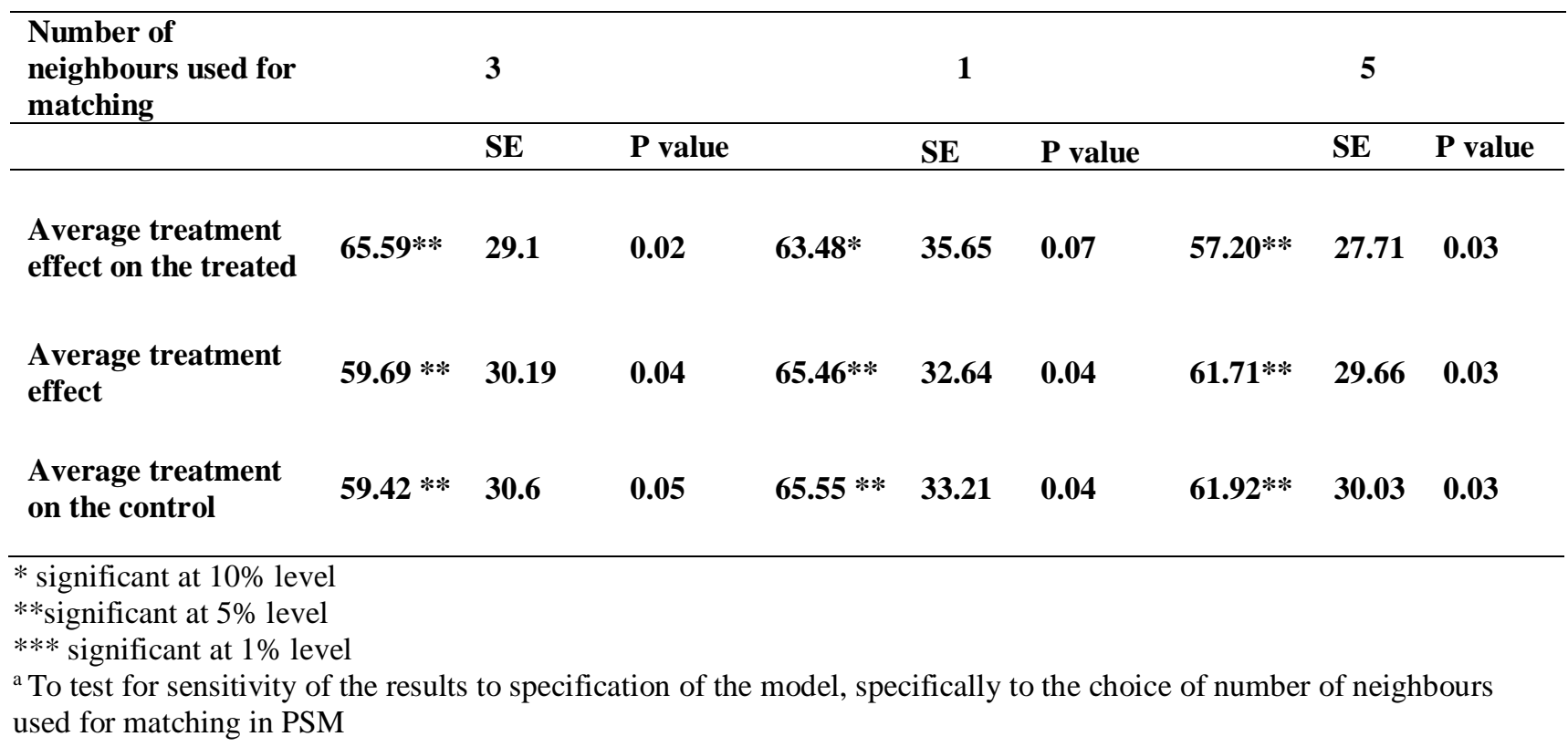

